\title{
Elections in a Multi-Party Political System
}

\author{
Yeolyong Sung \\ Korea Institute for Industrial Economics \& Trade, Seoul, South Korea \\ E-mail: ysung@kiet.re.kr \\ Received June 19, 2011; revised July 27, 2011; accepted August 5, 2011
}

\begin{abstract}
In a multi-party political system, candidates' policy points disperse in general even with two candidates when parties have different feasible policy sets. Also, it is shown that extremists can influence the political outcomes with a relatively small feasible policy set.
\end{abstract}

Keywords: Election, Multi-Party, Median Voter Result, Extremist

\section{Introduction}

In most cases of representative democracy, individual politicians by themselves have little power to influence political outcomes. Rather, they collectively obtain and wield political power through a party. For example, most candidates run for an election as a member of a party not as an individual, and actually their winning possibility is larger than independent candidates' by organizational and financial support of the party.

Either an individual politician becomes a member of an existing party of which policy stances contain his/her ideal or individuals with similar political purposes form a new party. Then individual politicians' political actions are governed by the political stance of the party they belong to, which divides the spectrum of political standpoints of the electorate. Parties pledge themselves on their own policy stances and competition among the parties with different policy stances is common in election. A candidate affiliated with a particular party must commit to his/her policy to be implemented within the party's given policy set which is a subset of the whole policy space.

This study focuses on elections in which the competition is among office-seeking partisan candidates whose policy set is constrained by the party they belong to. The objective of the study is to explain dispersion in candidates' policy points and the existence of influential extremists under a multi-party system with policy constraints. The model is different from the citizen-candidate model of Osborne and Slivinski [1] in that candidates are partisan and their preferences are policy irrelevant.

In this note, we look over simple two- and three-party examples and attempt to interpret the model. Also, we discuss the modeling and its extensions.

\section{The Basic Model}

At first, parties decide whether or not to enter an election. The parties which have decided to do nominate their own candidates for the election ${ }^{1}$ and they compete with each other for being elected by choosing a policy point to be implemented. In the voting stage, the voters vote for one candidate and the winner is determined by plurality rule.

The policy space is $X=[0,1]$ and each party is exogenously endowed with a compact feasible policy set, which is mutually exclusive with each other except for the boundaries and exhausts the policy space. Formally, party $i$ 's feasible policy set $X_{i} \subset X$ is a closed interval and $\bigcup_{i} X_{i}=X$ such that $X_{i} \cap X_{j}$ is an empty set or a singleton if $i \neq j$.

Each candidate commits to a policy point in the feasible policy set. Party $i$ 's policy point to be implemented if elected is denoted by $x_{i} \in X_{i}$. Politicians are office seekers, so the utility of party $i$ 's candidate is given by $u_{i}(w)=1_{\{i=w\}}(w)-c$, where $1_{A}(w)$ is an indicator function of the winning candidate, $w$, on event $A$ and $c>0$ is the running cost for the election. Thus, if a politician is nominated as a candidate and wins the election, then his/her utility is $1-c$; and if the candidate loses, then $-c$. We assume that the utility of a politician who does not enter the election is zero.

The running cost, $c$, is assumed to be sufficiently small relative to the expected benefit from entering the election unless the winning probability is zero. With the utility function specified above, it suffices to assume that

\footnotetext{
${ }^{1}$ We do not deal with issues of party primaries here. For them, see Cadigan and Janeba [2] and Owen and Grofman [3].
} 
$c$ is always less than the winning probability if it is strictly positive, which is the expected benefit from entering the election. Thus, the utility function implies that if a party expects that it will lose the election with probability 1 , then it does not enter the election because no member of the party wants to be a candidate.

The set of voters is a continuum $V=[0,1]$, and each voter's preference on the policy space is symmetric and single-peaked. Voters' ideal policy points are uniformly distributed on $X=[0,1]$. We assume that each voter votes for the most preferred candidate sincerely ${ }^{2}$. A candidate who obtains the most votes is elected and his/her announced policy is implemented. If there is a tie, each candidate with the most votes has equal probability of winning.

\section{Two-Party System}

Consider a two-party system with the Leftist ( $L$ ) party and the Rightist $(R)$ party. In this case, both parties enter the election only if they are balanced in terms of their policy stances. If the sizes of the feasible policy sets are different, only the party with the larger set enters the election and wins by acclamation. For example, let $\hat{x} \in(1 / 2,1]$ and suppose that $X_{L}=[0, \hat{x}]$ and $X_{R}=[\hat{x}, 1]$. Then the Leftist can win the election by an- nouncing any policy point $x_{L} \in(1-\hat{x}, \hat{x}]$ and so the Rightist does not enter the election because then it loses with probability 1 . Only when the feasible sets of the parties equally divide the policy space ( $\hat{x}=1 / 2$ ), both parties compete on the election and the policy points are $x_{L}=x_{R}=1 / 2$ with each party's winning probability of $1 / 2$.

\section{Three-Party System}

For convenience, suppose that three parties, the Leftist ( $L$ ), the Moderate $(M)$ and the Rightist $(R)$, represent three groups, respectively, corresponding to their feasible policy sets which divide the policy space symmetrically around the median $1 / 2$, that is, $X_{L}=[0, \bar{x}], X_{M}=[\bar{x}, 1-\bar{x}]$ and $X_{R}=[1-\bar{x}, 1]$ for some $\bar{x} \in[0,1 / 2]$. We have three kinds of electoral outcome depending on the value of $\bar{x}$. First, if $\bar{x} \in[0,1 / 6)$, the only candidate comes from the Moderate and is elected by choosing $x_{M} \in(3 \bar{x}, 1-3 \bar{x})$. Second, if $\bar{x} \in(1 / 6,1 / 2]$, only the two extremists enter the election with the policy points of $x_{L}=\bar{x}$ and $x_{R}=1-\bar{x}$, respectively. This example shows that the median voter result does not hold in two candidate competition because the candidates' policy choices are restricted out of the median. Third, if $\bar{x}=1 / 6$, all the three parties com-

\footnotetext{
${ }^{2}$ If it is assumed that the set of voters is a continuum and the number of the members of each party is finite, then the finite partisan voters' influence on the election is negligible.
}

pete on the election at the policies $x_{L}=1 / 6, x_{M}=1 / 2$ and $x_{R}=5 / 6$ with equal winning probability. The literature reports that equilibrium may not exist with three (or more) candidates (Cox [4], Osborne [5]), but the policy constraint that the median point cannot be shared by the candidates guarantees the existence of equilibrium.

\section{Conclusions}

The two-party and three-party competition in the above sections show that candidates' policy points disperse in general even with two candidates when parties have different feasible policy sets. The constraint on the policy sets makes the parties' entry decision strategic and leads to the dispersion in policies. Also, it is shown that in political systems with more than two parties, extremists can influence the political outcomes even though their feasible policy sets are relatively small, while a moderate can do so with a relatively large feasible set. This is because sincere voters close to an extremist's policy point cast the vote for the extremist even though their ideal lies in a moderate party's policy set.

In this note, only two- and three-party political systems were considered. But the analysis can be extended to an arbitrary $N$-party system in which the feasible policy sets of the parties divide the policy space symmetrically around the median voter's ideal point. The above results are preserved as well in the model with $N$ parties. There are a couple of things to be more studied in this research. First of all, endogenous party formation should be studied. In the basic model, the feasible policy set of a party was exogenously given. However, it is determined in the course of the formation or the evolution (expansion, contraction, mergence, or division) of the party $^{3}$. Second, if the candidate of a party was policy motivated within the feasible set, then he/she could not commit to a policy point ${ }^{4}$.

\section{References}

[1] M. J. Osborne and A. Slivinski, "A Model of Political Competition with Citizen-Candidates,” Quarterly Journal of Economics, Vol. 111, No. 1, 1996, pp. 65-96. doi: $10.2307 / 2946658$

[2] J. Cadigan and E. Janeba, "A Citizen-Candidate Model with Sequential Elections," Journal of Theoretical Politics, Vol. 14, No. 4, 2002, pp. 387-407. doi:10.1177/095162902774006804

[3] G. Owen and B. Grofman, "Two-Stage Electoral Compe-

\footnotetext{
${ }^{3}$ As an example of evolution, Owen and Grofman [3] attempt to explain dynamics of the split of the policy space in a two-party competition with primary election.

${ }^{4}$ For reference, Snyder and Ting [6] analyze a model of legislative policy making in which legislators have two means of communicating their preferences to voters: party labels and roll call votes.
} 
tition in Two-Party Contests: Persistent Divergence of Party Positions," Social Choice and Welfare, Vol. 26, No. 3, 2006, pp. 547-569. doi:10.1007/s00355-006-0087-1

[4] G. W. Cox, "Centripetal and Centrifugal Incentives in Electoral Systems," American Journal of Political Science, Vol. 34, No. 4, 1990, pp. 903-935.

doi:10.2307/2111465
[5] M. J. Osborne, "Candidate Positioning and Entry in a Political Competition,” Games and Economic Behavior, Vol. 5, No. 1, 1993, pp. 133-151. doi:10.1006/game.1993.1007

[6] J. M. Snyder and M. M. Ting, "Roll Calls, Party Labels, and Elections,” Political Analysis, Vol. 11, No. 4, 2003, pp. 419-444. doi:10.1093/pan/mpg025 